\title{
A Gestão do Empreendimento Rural: um estudo a PARTIR DE UM PROGRAMA DE TRANSFERÊNCIA DE TECNOLOGIA PARA PEQUENOS PRODUTORES
} I.

\author{
The Management of Rural Development: a study from a \\ program of technology transfer to small producers
}

\author{
Marcio Silva Borges \\ Professor da Universidade Federal Rural do Rio de Janeiro. Três Rios, RJ, Brasil. E-mail: msborges@hotmail.com \\ Cezar Augusto Miranda Guedes \\ Professor da Universidade Federal Rural do Rio de Janeiro. Seropédica, RJ, Brasil.E-mail: cezar.eco@gmail.com \\ Maria Cristina Drumond e Castro \\ Professor da Universidade Federal Rural do Rio de Janeiro. Três Rios, RJ, Brasil. E-mail: cristinadrumond2010@gmail.com
}

\section{Resumo}

A abertura do mercado lácteo nacional na década de 1990 expôs os baixos índices de eficiência técnica e de gestão, demonstrando a necessidade de criar ações para melhorias nesse sentido. Além disso, há dois processos convergentes que corroboram com os fatores citados: o primeiro internalizando índices como capacidade de fornecimento, produção em escala e nível de tecnologia empregada; e um segundo processo que caracteriza a adoção de um sistema de gestão eficiente para capacitar os produtores na utilização de tecnologias apropriadas resultando ganhos de produtividade e de rentabilidade para toda a cadeia. O objetivo deste trabalho consiste em analisar em que medida o Balde Cheio, programa criado pela EMBRAPA Pecuária Sudeste em 1999, pode funcionar como vetor de capacitação para o gerenciamento de pequenas propriedades leiteiras a partir da transferência de tecnologia. Os cinco meses de entrevistas in loco, na cidade de Valença - RJ, permitiram que se chegasse à conclusão de que o Balde Cheio possibilitou uma transferência de tecnologia eficiente e um sistema de gestão da propriedade compartilhada com extensionista rural, evidenciando vantagens e desvantagens nesse processo.

Palavras-chave: Transferência de Tecnologia. Gestão Rural. Agricultura Familiar.

\section{Abstract}

The opening of national dairy market in the 90's decade exposed low indexes of technical efficiency and management, providing evidence of improvements needed in this regard. In addition, there are two convergent processes that corroborate with the factors cited: the first internalizing indexes such as supply capacity, production in scale, and level of technology employed; and a second process, with the adoption of an efficient managament system, able to empower producers in the use of appropriate technologies resulting gains in productivity and profitability for the entire chain. The aim of this study was to examine to what extent the Balde Cheio project, created by EMBRAPA Pecuária Sudeste in 1999, can act training vector for managing small dairy properties from the transfer of technology. The five months of on-site interviews in the city of Valença - RJ allowed conclude that Balde Cheio enabled an efficient technology transfer a property management system shared with rural extension agent showing advantages and disadvantages in this process.

Keywords: Transfer of Technology. Rural Management. Family Farming. 


\section{INTRODUÇÃO}

A atividade leiteira no Brasil, ao longo de sua história, já viveu sucessivas crises, tanto na produção quanto no abastecimento, destacando-se a baixa produção e a produtividade, o baixo nível tecnológico utilizado, a elevada sazonalidade com alto custo de produção e a ausência de uma política global bem definida de longo prazo para o setor.

Dentre as cadeias produtivas do setor agropecuário, Vilela et al. (1999) afirmam que a do leite foi a que sofreu maiores transformações nos últimos anos. Tradicionalmente o mercado de lácteos no Brasil vivia sob uma forte intervenção do governo, impedindo de certa forma um desempenho eficiente. No início dos anos 90, algumas transformações começaram a acontecer, culminando com grandes mudanças em todos os segmentos da cadeia, principalmente na produção e economia, uma vez que tem forte participação na cesta básica e impacto no custo de vida. O Sistema Agroindustrial (SAG) do leite precisou se estruturar para se adequar à competição do mercado no cenário interno, como também do mercado externo.

Conforme Belik (1999), fatores como a proximidade das fontes de matéria-prima e a existência de mão de obra barata não mais servem de diferencial competitivo diante da abertura dos mercados e da busca incessante de qualidade e flexibilidade por parte das empresas. Os avanços proporcionados pela tecnologia aplicados ao campo e à indústria permitiram reduzir gradativamente as vantagens competitivas proporcionadas pelos recursos naturais. Por outro lado, o crescimento da competição tem levado à diversificação de produtos diante de um mercado cada vez mais sofisticado e ávido pela qualidade. Nesse particular, o baixo custo da mão de obra não pode ser apontado como diferencial competitivo para as empresas, pois na maior parte dos mercados a competição tem se voltado para outras questões não diretamente ligadas ao preço do produto, mas sim a sua qualidade, tecnologia $e$ as técnicas de gestão empregadas.

Sem dúvida, a mudança ocorrida no ambiente institucional, especialmente no tocante à desregulamentação do setor e à abertura comercial, promoveu uma nova dinâmica na cadeia produtiva láctea. No entanto, provocou um alto custo social decorrente da exclusão de muitos produtores rurais e do processo de concentração agroindustrial acelerado, assistindo cada vez mais ao aumento do poder das indústrias, dos atacadistas e dos varejistas.

Além da não estabilidade nos preços, a cadeia produtiva de lácteos é impactada frequentemente pelas políticas macroeconômicas, pelas políticas setoriais que nesse setor são altamente conjunturais, pelas variações climáticas e até mesmo pelo desempenho de outras culturas, à medida que o leite é uma atividade que muitos agricultores passam a apostar quando a sua atividade principal vai mal. Nesse sentido, programas governamentais de fomento poderiam estabelecer parcerias com fornecedores de insumos, prestadores de serviços, agentes financeiros. Outras empresas e organizações que atuam diretamente ou indiretamente no setor podem ser fontes de competitividade, já que facilitariam a estabilizar as relações das empresas; facilitar o acesso às novas tecnologias e disseminação de conhecimento; treinamentos com visitas periódicas de um técnico responsável visando a técnicas mais eficientes de gestão da propriedade rural, entre outras possibilidades.

Portanto, a alternativa de um programa de governo como o Balde Cheio facilitar as organizações produtivas de características familiares a terem acesso a serviços de assistência técnica ou veterinária a custos baixos e a técnicas de gestão rural, poderia em uma boa parte desta parcela à margem do processo de renovação do setor, manter seu emprego, gerando renda, cidadania e fixando o homem ao campo. Ainda que apenas uma parte dos produtores se adaptam a esses programas, este trabalho que ora se apresenta já se justifica importante por apontar suas vantagens e desvantagens.

\section{Gestão do Empreendimento Rural}

A incorporação da gestão no empreendimento rural facilita a inserção do produtor no mercado e permite estabelecer uma comunicação entre o produtor e os consumidores finais, por intermédio das agroindústrias e dos canais de distribuição.

Existem dois tipos de produtores, conforme ilustrado na Figura 1: (1) aqueles tidos como pequenos característicos do modelo familiar e (4) aqueles tidos 
como produtores de escala, característicos do modelo patronal.

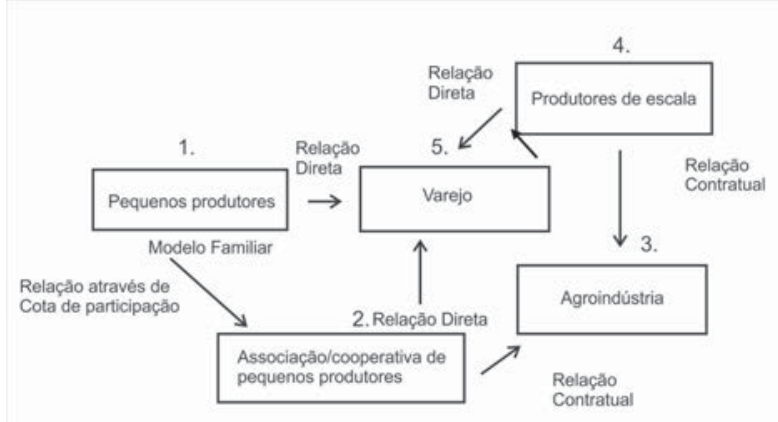

Figura 1: Relações estabelecidas entre produtores e consumidores na escala de produção láctea

Fonte: Adaptada de Nantes e Scarpelli (2007, p. 567)

No modelo familiar, os produtores (1) escoam a produção diretamente para os consumidores via venda no segmento varejo (5) ou escoam para a associação ou cooperativa (2) mediante relação por cota de participação. A associação ou cooperativa (2), por sua vez, direciona a produção para o varejo (5) em relação direta ou para as agroindústrias (3) por meio de relação contratual e estas por sua vez vendem sua produção ao mercado consumidor (5). Nesse caso, as agroindústrias mantêm contratos com as cooperativas ou associação para entregar no prazo certo e em quantidade contratual, procedimento, de certa forma, inviável ao produtor familiar, que, na maioria dos casos, não tem capacidade produtiva para atender à demanda da agroindústria.

No modelo patronal, com estrutura mais empreendedora, o produtor em escala (4) consegue enviar a produção para o mercado varejo (5), numa relação direta, ou para a agroindústria (3), por meio de relação contratual, isso porque o produtor usufrui de aparato tecnológico e gerencial razoável, conseguindo, portanto, atender à demanda dos segmentos do varejo $e$ da agroindústria.

No Quadro 1 são descritas as principais características dos meios de distribuição vinculados aos empreendimentos rurais. Cabe ao produtor rural integrar um dos elos da cadeia de produção específica ao seu ramo produtivo. Ademais, a estrutura organizacional do empreendimento rural deve ser similar ao de uma empresa para que este possa conhecer o mercado, incrementar relacionamento com o segmento industrial e de canais de distribuição. Antes, torna-se necessário planejar investimentos, reduzir custos e perdas e proceder com atualização tecnológica.

De acordo com Nantes e Scarpelli (2007), a aprendizagem e a incorporação de tecnologia são focos que o produtor rural tem que incorporar na estrutura organizacional de seu empreendimento. A aprendizagem possibilita a capacitação constante de todas as pessoas envolvidas no processo de produção e ajuda na manutenção da aprendizagem tanto individual como organizacional nas relações internas e externas da empresa rural. Já a incorporação de tecnologia pode ajudar na maximização dos lucros, em tornar a empresa mais competitiva $e$ se adequar às exigências da cadeia produtiva.

\begin{tabular}{|c|c|c|}
\hline $\begin{array}{l}\text { Destino dA } \\
\text { PRODUÇão }\end{array}$ & DefinIÇÃo & $\begin{array}{c}\text { Características } \\
\text { VINCULAdAS }\end{array}$ \\
\hline Agroindústrias & $\begin{array}{l}\text { São indústrias } \\
\text { processadoras de } \\
\text { produtos do meio } \\
\text { agrícola, como } \\
\text { cana de açúcar, } \\
\text { leite, milho, arroz. }\end{array}$ & $\begin{array}{l}\text { - qualidade do produto; } \\
\text { maturação homogênea; } \\
\text { isento de praga } \\
\text { e doenças; } \\
\text { sem mistura de } \\
\text { variedade; } \\
\text { manutenção de } \\
\text { propriedades físicas } \\
\text { e químicas; } \\
\text { - menor preço; } \\
\text { - disponibilidade e } \\
\text { diversidade de opção; } \\
\text { - oferta constante; } \\
\text { - volume certo; } \\
\text { - investimento em } \\
\text { tecnologia; }\end{array}$ \\
\hline $\begin{array}{l}\text { Canais de } \\
\text { Distribuição }\end{array}$ & $\begin{array}{l}\text { Trata-se de locais } \\
\text { intermediários } \\
\text { de escoamento } \\
\text { da produção } \\
\text { situados entre } \\
\text { o produtor e o } \\
\text { consumidor final, } \\
\text { constituídos por } \\
\text { supermercados, } \\
\text { centrais de } \\
\text { abastecimento } \\
\text { e atacadistas. }\end{array}$ & $\begin{array}{l}\text { - exigência de } \\
\text { incorporação de valor } \\
\text { ao produto: embalagens } \\
\text { e armazenamento; } \\
\text { - exigência de } \\
\text { uniformidade da cor, } \\
\text { tamanho e textura } \\
\text { e sabor do produto } \\
\text { (atributos físicos } \\
\text { e químicos). }\end{array}$ \\
\hline
\end{tabular}

Quadro 1: Características dos meios de distribuição vinculados aos empreendimentos rurais na cadeia produtiva Fonte: Adaptado de Nantes e Scarpelli (2007)

Um estudo desenvolvido pelo Instituto de Estudos Sociais Avançados (IESA), em 2009, da Espanha demonstrou a importância qualitativa para um empreendimento rural: centros de formação para pequenos 
produtores. Neles os produtores de leite poderiam ter conhecimento sobre o seu negócio, acesso à banda larga e apresentação de legislação sanitária vigente. Além disso, o estudo faz menção à infraestrutura adequada de um sistema viário, que, em conjunto poderiam desenvolver muitos territórios rurais.

\subsection{Estratégias para Empreendimentos Rurais de Pequeno Porte}

Segundo estudos de Nantes e Scarpelli (2007), a implantação de estratégias para empreendimentos rurais de pequeno porte se enquadra em duas etapas:

Primeira - o produtor deve definir claramente o que pretende produzir, de acordo com: (1) recursos disponíveis ou fatores de produção (o solo, o clima, água, equipamentos, benfeitorias e condições econômicas); (2) a vocação natural do produtor (disposição para trabalhar com determinado produto na propriedade); e (3) as condições do mercado (estar informado sobre o mercado $e$ as tendências de crescimento relacionado ao tipo de produto adotado). A reflexão sobre estes três itens é fundamental para minimizar possíveis prejuízos futuros.

Segunda - sugere-se ao produtor optar por uma das três estratégias comuns no mercado: (1) associativismo e parcerias; (2) a agregação de valor ao produto; e (3) diferenciação de produtos $^{1}$.

Associativismo e parcerias apresentam-se como uma alternativa ou solução em que o produtor pode minimizar impactos relacionados à sua inserção $e$ permanência na cadeia produtiva, pois é realizada por meio da racionalização do trabalho e dos custos (NANTES; SCARPELLI, 2007). Nesse tipo de estratégia por ser uma relação bilateral, a parceria deve ser estabelecida mediante contrato, a fim de assegurar cumprimento das cláusulas constantes e, portanto, não gerar prejuízos aos contratantes. Entre as principais características desse tipo de estratégia, segundo Nantes e Scarpelli (2007), encontram-se:

\footnotetext{
${ }^{1}$ Agregar valor, de acordo com Shultz e Kitchen (1997), é um atributo intangível encontrado na percepção do cliente sobre o "preço de prateleira". O valor percebido ocorre no ato da aquisição do bem através da disponibilização segundo interesses do cliente, na forma de atendimento, nas facilidades ofertadas, no nível de relacionamento, nos serviços pós-venda (garantia, assistência...), enfim, um conjunto de atitudes e ações que somente o Capital Intelectual promove. O mesmo não se dá com a estratégia de diferenciação, pois para outro nicho de consumidores a etiqueta (marca) valoriza em muito o produto.
}
a) trabalho e recursos operacionais;
b) participação nas cotas de produção;
c) ganho de escala;
d) vantagens na comercialização dos produtos;
e) redução de preços dos insumos;
f) aproveitamento das potencialidades dos pro- dutores;
g) domínio nas decisões; $e$
h) viabilidade técnica e econômica.

\subsection{Fatores que Dificultam a Utilização de Técnicas de Gestão na Propriedade}

Várias pesquisas e estudos sobre restrições tecnológicas na cadeia produtiva do leite identificaram inúmeros fatores que dificultam a utilização da tecnologia de gestão em nível de propriedade (VILELA et al., 1999).

Partindo da premissa que a grande maioria dos proprietários empreendedores que produzem leite no Brasil é formada de pequenos produtores ${ }^{2}$, que utilizam predominantemente a mão de obra familiar e, em geral, administram seus negócios com base quase exclusivamente na experiência adquirida ao longo da vida, com praticamente nenhum treinamento formal em administração. À medida que aumenta o volume dos negócios, o produtor de leite tende a utilizar proporcionalmente menos mão de obra familiar; passa a depender de ajuda externa. Mas não diferem tanto dos pequenos quando se trata da capacidade gerencial (ALVES, 2004; EPAGRI, 2005).

Alguns fatores internos ajudam a explicar a dificuldade em se utilizar técnicas de gestão apropriadas:

a) Qualificação profissional: a deficiência na educação formal (medida pelo nível de escolaridade) ou falta de experiência (expressa pelo número de anos na atividade) do empregador limitam a capacidade de decodificação de mensagens técnicas e conceituais. Normalmente, o nível de habilitação dos empregados também é baixo, tornando a administração de recursos humanos especialmente difíceis. Tudo isso dificulta a capacidade de coleta dos dados da propriedade, necessários ao processo

\footnotetext{
${ }^{2}$ Para o autor são considerados pequenos aqueles que produzem menos de 200 litros de leite por dia no Brasil.
} 
de gestão, dentre as quais o domínio de conceitos econômico-financeiros e a utilização de informática (para o armazenamento correto e análise dos dados), dificultam a geração de informações importantes para tomada de decisão (CANZIANI, 2001; NORONHA et al., 2001).

b) A gestão de recursos humanos: esta é, talvez, a área mais difícil de ser administrada na propriedade. Primeiro porque o administrador em geral não está preparado para delegar funções, liderar pessoas e manter um bom nível de motivação em sua equipe, mesmo quando são da própria família. E segundo porque a legislação trabalhista atual não é compatível com a atividade leiteira, uma vez que se torna difícil mensurar o que é hora normal de trabalho $e$ o que é hora extra. E o custo da mão de obra é alto mesmo quando o salário é muito baixo, o que tende a desagradar ao mesmo tempo o empregador e o empregado. Há necessidade urgente de se investir na capacitação em recursos humanos, em geral, e na área administrativa em particular (VOLPI; BRESSAN, 2001).

c) Gestão financeira: o fato da venda do leite produzir um fluxo de caixa mensal, coisa rara na agropecuária, tende a colocar sobre ela a responsabilidade de financiar o capital de custeio das propriedades diversificadas $e$ a manutenção das despesas da família (EPAGRI, 2005). Esse papel de provedora de capital de custeio da propriedade em seu todo nem sempre é reconhecido e valorizado, subestimando-se a sua importância estratégica na gestão dos negócios dos produtos e sua família e, consequentemente, os resultados econômicos desta atividade em particular.

Existem também fatores externos que são determinantes para a não utilização de técnicas de gestão:

a) Assistência técnica: é fato que a assistência técnica privada assumiu o papel da assistência técnica pública. Mas continua focada principalmente na tecnologia de produção ${ }^{3}$. No entanto, Batalha (2005) relata após pesquisa realizada com os agentes do agronegócio, o perfil ideal

3 Exemplo de assistências técnicas publica e privadas com foco na gestão de propriedades: Empresa de Pesquisa Agropecuária e Extensão Rural S.A, em Santa Catarina (EPAGRI, 2005); SEBRAE-SENAR no Paraná (Peres et al., 2003 org.), varias iniciativas mais recentes em Goiás (SOUZA LIMA JR, 2005) tais como Projeto Mais Leite (iniciativa privada), Programa Rede Leite (idem), Programa de Recuperação da Rentabilidade da Pecuária Leiteira (SENAR-GO/FAEG/EMBRAPA GADO DE LEITE), Gera Leite e outros. do profissional que demandam. Dentre os seis tópicos escolhidos, a área de Economia e Gestão só perde para Qualidades Pessoais e Comunicação/Expressão, e ganha de Tecnologia de Produção, Sistemas de Informação $e$ Experiência Profissional. Conclui-se, também, que as instituições de ensino superior, incluindo pós-graduação, continuam despreparadas para atender à demanda, principalmente na área de gestão rural.

b) Tipo e assimetria de informação: as informações externas provenientes dos mais diversos órgãos de comunicação (televisão, rádio, boletins técnicos, revistas especializadas etc.) dão maior ênfase às tecnologias de produção $e$, aos preços de mercado. Quando focalizam casos de empresas bem-sucedidas, quase sempre, exageram no otimismo quanto à viabilidade dos investimentos na produção de leite, sem a devida ênfase nas exigências de qualificação dos recursos humanos necessários para gerir esse tipo de negócio e os riscos inerentes a ele.

Na negociação de preços, condições de financiamento e questões trabalhistas, com os diversos clientes, o produtor não tem as mesmas informações disponíveis para o seu interlocutor e não tem poder de mercado, sendo praticamente um tomador de preço. Isso o coloca em posição nitidamente de desvantagem.

\subsection{Teoria e Realidade na Gestão da Propriedade de Leite}

Uma das formas práticas de estudar a gestão das empresas tem sido por meio de suas funções e áreas de atuação. Planejamento, organização, direção e controle são as funções clássicas da administração das empresas e produção, recursos humanos, finanças e comercialização e marketing, são áreas administrativas sobre as quais essas quatro funções são exercidas na empresa. Ao focar o problema de gestão sob a ótica desta teoria, pode-se dispensar a discussão, às vezes, pouco produtiva, sobre o próprio conceito de gestão.

Drucker (1995) recomenda para qualquer organização, com ou sem fins lucrativos, que se focalize a gestão a partir de cinco perguntas básicas: Qual é o nosso negócio? Quem é o nosso cliente? O que o cliente mais valoriza nesse negócio? Quais resultados estão sendo alcançados? Qual é o nosso plano? 
Considerando apenas propriedades leiteiras que visam primordialmente não apenas o lucro a curto $e$ em médio prazo, mas também à sustentabilidade de suas operações em longo prazo, a resposta da primeira pergunta parece óbvia, pois seria leite. Infelizmente, grande número de produtores ${ }^{4}$ pensa assim. Colocam exagerada ênfase na tecnologia de produção de leite, tais como a introdução de silagem, formação de pastejo rotacionado e adoção de inseminação artificial. Todavia, esta postura pode ter consequências sérias na gestão da empresa quando deixa de considerar a importância das atividades complementares num eventual plano de negócios (NORONHA, 2001).

Em relação a quem é o cliente, a resposta parece ser fácil, pode ser a cooperativa local, um laticínio, o queijeiro que pagar melhor na região, a dona de casa que recebe o leite na porta, ou uma combinação deles. Admitindo que o cliente seja a cooperativa, em tese, isso simplifica sobremaneira algumas decisões operacionais na área de comercialização, tanto na compra de insumos como na venda do leite. Mas a atividade leiteira gera outros produtos que a cooperativa não recebe (Figura 2), como touros e matrizes descartados, bezerros de valor comercial, bezerras ou novilhas que excedem a necessidade de reposição ${ }^{5}$, etc. Esses produtos também precisam ser vendidos a outros clientes.

Logo, a gestão da comercialização não é tão simples quanto parece.

Noronha (2001) continua com a análise da próxima pergunta em relação à valorização do produto. É sabido que a processadora de leite, um dos principais destinos de entrega, valoriza a quantidade e a qualidade do leite. Mas não os demais produtos. Até que ponto então deveria o produtor focar na produção e qualidade do seu produto principal em detrimento da qualidade (e talvez quantidade) dos produtos complementares nesta atividade de produtos juntos (joint products)? O que se observa com frequência é uma atitude cautelosa do produtor no intuito de tentar atender a todos os seus clientes, até mesmo para reduzir riscos. Assim, muitos evitam a utilização de rebanhos altamente especializados na produção de leite, além de

\footnotetext{
${ }^{4} \mathrm{E}$ talvez a maioria dos que lhes prestam assessoria ou assistência técnica também.

${ }^{5}$ Vacas velhas e/ou com problemas de sanidade, com baixa produtividade e nível aquém de reprodução e por causa de acidentes, são descartadas. A taxa de reposição de acordo com o professor Edinaldo Bezerra pode oscilar entre 15 e $25 \%$ ao ano.
}

conduzirem outras atividades agrícolas e pecuárias na propriedade. Isso aumenta ainda mais a complexidade da gestão e pode induzir à perda de foco.

Em relação aos resultados alcançados observa-se com muita frequência na prática que o produtor de leite só fica sabendo o resultado econômico de seu negócio quando recebe o saldo de sua conta na cooperativa. Assim mesmo, este resultado é parcial porque costuma não ter controle das outras atividades da fazenda. Neste momento reinicia o processo de administração de finanças. Um saldo positivo, sinal de bons resultados da produção de leite, passa a ser a salvação da empresa. Atende às necessidades da família, o custeio da fazenda e na realização de novos projetos de investimentos produtivos.

Finalmente, os autores relatam o último questionamento a ser ponderado. Quando se refere à existência de um plano para a propriedade leiteira, quase sempre a resposta é negativa, não existe um plano formal de negócios. É a partir de um plano inicial, por mais simples que seja que os agentes de assistência técnica iniciam seu trabalho com os produtores e a busca por crédito nas instituições financeiras se facilita.

As dúvidas anteriores ajudam a mostrar, mesmo de forma simplificada, a complexidade da gestão dos negócios nas diversas áreas da fazenda. Diante disso, Noronha (2001) afirma que o problema central de gestão dos produtores de leite brasileiros reside na percepção falsa de que sabendo produzir, tudo mais se resolve satisfatoriamente. O domínio da produção deve vir acompanhado da existência de assistência técnica eficaz, treinamento, capital, boas estradas, etc.

\section{A Inovação Tecnológica Rural}

Os sistemas de produção de leite in natura no Brasil são bastante heterogêneos. Existem produtores que trabalham com tecnologias modernas e outros rudimentares. Por isso, antes de avaliar os efeitos do processo de modernização e de adaptação a novas e/ ou diferentes tecnologias sobre os produtores de leite no Brasil, é necessário estabelecer uma tipologia dos produtores de acordo com a sua exploração (Tabela 1). Para alguns autores, a classificação das propriedades pode depender do tipo de gestão adotada: familiar ou patronal; da tecnologia utilizada: especializada ou 
não especializada; e por fim, outros as denominam de comerciais ou para subsistência.

Tabela 1: Classificação das propriedades rurais.

\begin{tabular}{|c|c|c|c|}
\hline & Gestão & Tecnologia & VendA \\
\hline $\begin{array}{c}\text { Nantes e } \\
\text { Scarpelli } \\
(2007)\end{array}$ & $\begin{array}{c}\text { Pequenas/ } \\
\text { Familiares } \\
\text { De escala/ } \\
\text { Patronal }\end{array}$ & & \\
\hline Jank (1999) & & $\begin{array}{l}\text { Especializadas } \\
\text { e Não } \\
\text { Especializadas }\end{array}$ & \\
\hline $\begin{array}{c}\text { Provezano } \\
\text { Gomes (1999) }\end{array}$ & & & $\begin{array}{c}\text { Comerciais } \\
\text { e Não } \\
\text { Comerciais }\end{array}$ \\
\hline
\end{tabular}

Fonte: Adaptada de Nantes e Scarpelli (2007), Jank (1999) e Provezano Gomes (1999)

Com tantas formas de classificação e com diferentes níveis de especialização, o Brasil como muitos outros países, tem tentado mudar um padrão tecnológico de modelo linear de Pesquisa e Desenvolvimento (P\&D), em que as inovações desenvolvidas pela ciência são posteriormente transmitidas para os usuários, para um modelo mais dinâmico em que os usuários desempenham um papel mais ativo na inovação. Neste último caso, a inovação tecnológica eficaz é vista como um processo de longo prazo que envolve várias etapas, atores múltiplos e complexos acordos entre os atores (BESSANT; RUSH, 1993). Inovação, mais do que a tecnologia em si, deve ser entendida como um processo multidimensional, com pelo menos três dimensões: administrativa/tecnológica; produto/processo e incremental/radical (COOPER, 1998; KLERKX; LEEUWIS, 2008).

No entanto, muita inovação tecnológica desenvolvida pela pesquisa aplicada permanece em fase de protótipo ou piloto e não alcança os campos dos agricultores. A pesquisa agrícola pública e extensão tende a universalizar e ignorar as complexidades e contradições inerentes às inovações de execução (EDGE, 1995). Por exemplo, as tecnologias de lácteos e muitos serviços de apoio, implementados como parte de um programa do governo (cisternas, inseminação artificial, cursos para aumentar a qualidade do leite cru, cursos sobre as práticas de vacinação e tanques de resfriamento de expansão) foram concebidos sem referência às condições locais. Questões podem ser levantadas sobre o benefício da inseminação artificial em um rebanho faminto, a utilidade de uma variedade nova de relva em casos de extremamente baixa fertilidade do solo, a relevância do crédito bancário para a construção de uma sala de ordenha, onde o rebanho não é saudável, ou o financiamento de um tanque de resfriamento sem a devida tensão elétrica e constante na propriedade, $e$ assim por diante. No entanto, tais situações são predominantes na pecuária leiteira familiar.

A maioria dos programas do governo assume que o uso de uma nova tecnologia, uma vez introduzida será continuado, o que normalmente não ocorre, onde pouca atenção tem sido dada à formação da competência dos utilizadores finais (BESSANT; RUSH, 1993). Além disso, após os cortes no orçamento federal na década de 1990, serviços de extensão agrícola no Brasil careceram de recursos humanos e de capital (IBGE, 2006) e muitos outros serviços de extensão e centros de tecnologia baseados no estado, têm desde então, parado de funcionar (TEIXEIRA, 2004). Os dados do censo nacional de 2006 mostram que esse baixo nível de apoio técnico persiste onde apenas $22 \%$ dos agricultores declararam ter recebido algum apoio da assistência técnica (Figura 2), contrastando com uma grande maioria formada por $78 \%$ que nunca receberam a visita de técnico público ou privado.

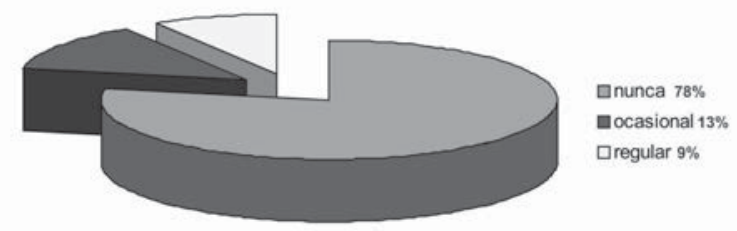

Figura 2: Assistência técnica rural no Brasil Fonte: Censo Agropecuário de 2006 por Vilela (2012)

Em aparente contraste com esta ênfase em pesquisa de ponta e baixo investimento em programas de extensão, o discurso oficial de desenvolvimento na década de 90 deu mais peso a incorporação de agricultores familiares em programas de intervenção. No entanto, os esforços para colocar a agricultura familiar no centro do processo de transferência de tecnologia falharam (OLINGER, 1998). Embora alguns estados tenham melhorado a sua assistência aos pequenos agricultores, a nível nacional, tem havido 
uma tendência para apoiar os agricultores mais ricos e instruídos. Em 2006, os agricultores assistidos tinham em média 228 hectares (ha) enquanto os não assistidos tinham apenas 42 ha. Apenas $16,8 \%$ dos agricultores com escolaridade incompleta recebeu alguma assistência técnica enquanto $44,7 \%$ dos agricultores com estudos de nível universitário declarou que eles tinham recebido alguma assistência (IBGE, 2006). Esse viés não é o resultado de diferentes respostas dos agricultores, como a maioria dos produtores de leite manifestou interesse em receber assistência técnica e que não foram atendidos (GOMES; FERREIRA FILHO, 2006).

Nos dados da Tabela 2 , pode-se observar que a estratégia comercial para a venda de tecnologia não está disponível para todos, ainda que exista uma promoção de técnicas modernas e revolucionárias como solução, a "velha" tecnologia para agricultores de baixa renda persiste em existir. O pacote parece trabalhar para grandes fazendas, e não é tão apropriado para os sistemas generalizados de baixa intensidade de pastejo com vacas zebuínas. A grande maioria dos agricultores familiares brasileiros não pode pagar tal pacote, sublinhando a diferença entre o sistema de P\&D e da realidade dos agricultores familiares.

Tabela 2: Investimento em tecnologia em 2012.

\begin{tabular}{|ccccc|}
\hline \multicolumn{5}{|c|}{ ESTABELECIMENTOS QUE COMERCIALIZAM LEITE (UNIDADES) } \\
\hline $\begin{array}{c}\text { Total do } \\
\text { País }\end{array}$ & $\begin{array}{c}\text { Tanques de } \\
\text { Resfriamento }\end{array}$ & $\begin{array}{c}\text { Ordenha } \\
\text { Mecânica }\end{array}$ & $\begin{array}{c}\text { Inseminação } \\
\text { Artificial }\end{array}$ & $\begin{array}{c}\text { Transferência } \\
\text { de Embrióes }\end{array}$ \\
\hline 871.707 & 145.595 & 20.776 & 6.546 & 90 \\
\hline
\end{tabular}

Fonte: Censo Agropecuário 2006 (IBGE, 2006), Adaptado por Vilela (2012)

Outro fator que influencia as taxas de adoção de novas tecnologias é a capacidade de formação limitada. Em São Paulo, por exemplo, o SENAR-SP ${ }^{6}$ realiza cerca de 11.000 sessões de formação em produção de gado cada ano, envolvendo mais de 160 mil agricultores e empregados (SENAR, 2009). No entanto, o curto período de formação (em média menos de duas horas por pessoa) e pela falta de ajuste entre o

\footnotetext{
${ }^{6}$ O SENAR foi criado com a constituição de 1988 e faz parte do sistema $\mathrm{S}$, e, portanto, trata-se de uma organização paraestatal, ou seja, atividade exercida por entidades privadas, mas com conotação social ou de interesse público. É financiado por uma contribuição obrigatória por todos os empregadores (produtores rurais). Era para ter um papel muito importante, mas depende do município e na maioria dos casos não cumpre um papel relevante, conferir em: < http://lfg.jusbrasil.com.br/noticias/1927016/o-que-se-entende-por-parafiscalidade-joice-de-souza-bezerra $>$.
}

conteúdo da formação fornecida e necessidades dos agricultores significa que eles não são muito eficazes. Em suma, a natureza da tecnologia recomendada e os programas de formação oferecidos desconsideraram a complexidade da produção de leite e as múltiplas dimensões de qualquer processo de inovação.

Para contribuir com a temática de difusão de tecnologia e gestão, uma pesquisa realizada pela Federação da Agricultura, Pecuária e Pesca do Estado do Rio de Janeiro -FAERJ (2010) aponta entre os pequenos produtores de leite fluminense uma baixa qualificação, pouca transferência de tecnologia, qualidade do leite e sanidade do rebanho. Conforme a Tabela 3, em 2009 apenas $9,8 \%$ dos produtores fluminenses no estrato de produção até 50 litros de leite por dia utilizava o tanque para resfriar leite, variando até $95 \%$, no estrato acima de 400 litros. Quanto à ordenha mecânica entre os entrevistados que produzem até 50 litros, ninguém adota esta tecnologia, enquanto entre os produtores que produzem acima de 400 litros, 95\% a adotam.

Especificamente à gestão da propriedade, apenas $11,1 \%$ dos pequenos produtores praticavam algum tipo de planejamento e controle de sua propriedade e produção tais como: cálculo do custo de produção, conhecimento sobre o mercado do leite, sanidade do rebanho, normatização sanitária, qualidade do leite entre outros. No entanto, até mesmo os grandes produtores que produzem acima de 400 litros por dia possuem um nível de gerenciamento baixo com $15 \%$ das propriedades atendidas por esse controle.

Tabela 3: Nível tecnológico e de gerenciamento da propriedade do Estado do Rio de Janeiro em 2009

\begin{tabular}{|c|c|c|c|c|c|}
\hline 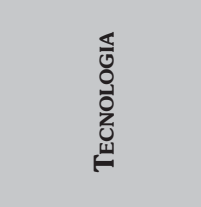 & 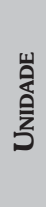 & 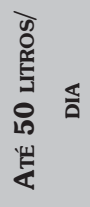 & 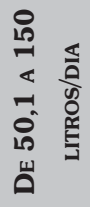 & 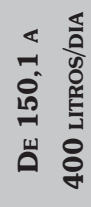 & 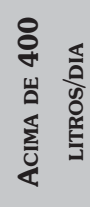 \\
\hline $\begin{array}{l}\text { Picadeira de } \\
\text { forragens }\end{array}$ & $\%$ & 82,8 & 91,5 & 97,1 & 100 \\
\hline $\begin{array}{l}\text { Tanque para } \\
\text { resfriamento }\end{array}$ & $\%$ & 9,8 & 17,1 & 65,7 & 95 \\
\hline $\begin{array}{l}\text { Botijão de } \\
\text { sêmen }\end{array}$ & $\%$ & 0,6 & 4,9 & 31,4 & 55 \\
\hline $\begin{array}{l}\text { Ordenhadeira } \\
\text { Mecânica }\end{array}$ & $\%$ & - & 12,2 & 45,7 & 95 \\
\hline $\begin{array}{l}\text { Equipamentos } \\
\text { de irrigação }\end{array}$ & $\%$ & 4,9 & 11 & 17,1 & 30 \\
\hline
\end{tabular}




\begin{tabular}{|c|c|c|c|c|c|}
\hline $\begin{array}{c}\text { Qualidade } \\
\text { do leite }\end{array}$ & $\%$ & 15,4 & 15,9 & 20,0 & 10 \\
\hline $\begin{array}{c}\text { Gerenciamento } \\
\text { da propriedade }\end{array}$ & $\%$ & 11,1 & 14,6 & 11,4 & 15 \\
\hline $\begin{array}{c}\text { Melhoramento } \\
\text { genético }\end{array}$ & $\%$ & 7,4 & 9,8 & 5,7 & 20 \\
\hline $\begin{array}{c}\text { Alimentação } \\
\text { do rebanho }\end{array}$ & $\%$ & 17,3 & 18,3 & 25,7 & 15 \\
\hline $\begin{array}{c}\text { Sanidade do } \\
\text { rebanho }\end{array}$ & $\%$ & 9,9 & 8,5 & 8,6 & 10 \\
\hline
\end{tabular}

Fonte: Adaptada de FAERJ (2010)

Por essa razão, Romeiro (2004) relata o problema de geração de conhecimento, do discurso para a prática, que está na dificuldade de avaliação das alternativas tecnológicas, problemática esta que, historicamente, se deve menos a um problema de falta de conhecimento tecnocientífico ${ }^{7}$, do que às polarizações de cunho ideológico-econômico que opõem críticos informados por visões idílicas da realidade aos defensores do status quo cujos apelos à objetividade e ao realismo sobre as necessidades humanas se torna suspeito pelos interesses do agribusiness que direta ou indiretamente representam.

No Brasil, o modelo predominante de P\&D continua a ser a transferência convencional de modelo de tecnologia (de cima para baixo, linear, modelo, modelo de um modo padrão). Modelos inclusivos incentivando uma maior participação dos agricultores não prosperaram no Brasil devido à falta de apoio dos serviços governamentais de extensão e sua relativa negligência por parte da comunidade científica local (TEIXEIRA, 2004). Muitos políticos e uma grande parte da comunidade científica dividem uma forte visão de que a inovação é mais bem abordada pela pesquisa de ponta, como genomas, nanotecnologia e observações através de sensoriamento remoto via-satélite. No entanto, a eficácia de tal pesquisa (fundamental e aplicada) em nível da agricultura é questionada por outros. Schwartzman (2002) mostra que, apesar de todos os fundos de pesquisa e recursos humanos investidos, houve poucas melhorias quantificáveis na produção agrícola. Vários fatores discutidos na literatura geral

\footnotetext{
${ }^{7}$ De acordo com o autor, a dificuldade em se transmitir conhecimento a uma parte dos pequenos produtores se deve à dificuldade que os programas concebidos pelo Estado cheguem até eles. Ele afirma que a tecnologia e os especialistas existem. Outra parte, não se adapta ao modelo imposto pelo agribusiness.
}

sobre o desenvolvimento de tecnologia também desempenham um papel no caso brasileiro.

Guedes e Silva (2005) afirmam que a agricultura familiar, quando possível, deve-se especializar em produtos específicos ancorados no território, na perspectiva das denominações territoriais e outros signos distintivos onde a grande empresa não pode competir, pela própria natureza do empreendimento. De acordo com os autores, surge a necessidade de se fomentar inovações que valorizem o trabalho $e$ o território abrindo novas frentes de riqueza e trabalho. E seguem afirmando que o saber localizado é compatível com os avanços tecnológicos e, a ciência, não deve estar a serviço apenas da lógica dos grandes blocos de capital, adotando, assim, uma perspectiva não linear na elaboração de programas de fomento locais.

As consequências no campo de uma tecnologia adequada e pensada ao local colaboram com a distinção de produtos diferenciados (oportunidades), em que, de acordo com Boehlje e Eidman (1984), os produtores de leite, que apresentam maior capacidade gerencial, administrativa ou tecnológica, conseguem melhorar de vida enquanto os outros, com os mesmos recursos produtivos e humanos, permanecem estagnados ou entram em decadência por não apresentarem a mesma capacidade. E essa é a realidade, também, de produtores nos Estados Unidos, em que a educação formal deles apresenta nível bem mais elevado e menor variabilidade entre eles. Apesar de sua reconhecida importância, a tecnologia de gestão de propriedades agropecuárias, no Brasil, ainda deixa muito a desejar8 (MEIRA, 1996; DALMAZO; ALBERTONI, 1991).

A inovação tecnológica $e$ a gestão rural no processo da globalização tornaram-se procedimentos significativos e importantes para o aumento da competitividade entre empresas nacionais e multinacionais. No cenário internacional, a competição efetivada por intermédio das multinacionais acabou por impulsionar os fluxos de bens, serviços e conhecimentos que perpassaram as fronteiras nacionais, incrementando as relações comerciais e a difusão de inovações tecnológicas, aumentando, dessa forma, o poder econômico

\footnotetext{
${ }^{8}$ Para uma análise mais completa do problema de assistência administrativa aos produtores da agropecuária brasileira veja Canziani (2001) e EPAGRI (2005).
} 
das empresas ${ }^{9}$ dos países integrantes da Organização para a Cooperação e Desenvolvimento Econômico $(\mathrm{OCDE})^{10}$.

Souza Lima Jr. (2005) se utiliza da ordenha mecânica como figura simbólica de moderna tecnologia de produção de leite, descreve o problema de gestão da seguinte forma: para desenvolver a atividade principal de manejar e ordenhar vacas com eficiência nos sistemas produtivos de leite no Brasil, além do saber localizado, o produtor também tem que executar adequadamente tantas outras atividades periféricas (Figura 3), como a produção de volumosos, a suplementação com concentrados ${ }^{11}$, o manejo reprodutivo e sanitário, a mecanização, as instalações, o melhoramento genético, a cria e a recria e a comercialização. Em realidade, são várias unidades de negócio relacionadas ao mesmo processo de produção. Isso representa uma grande complexidade gerencial para um empresário, pouco preparado para tanto.

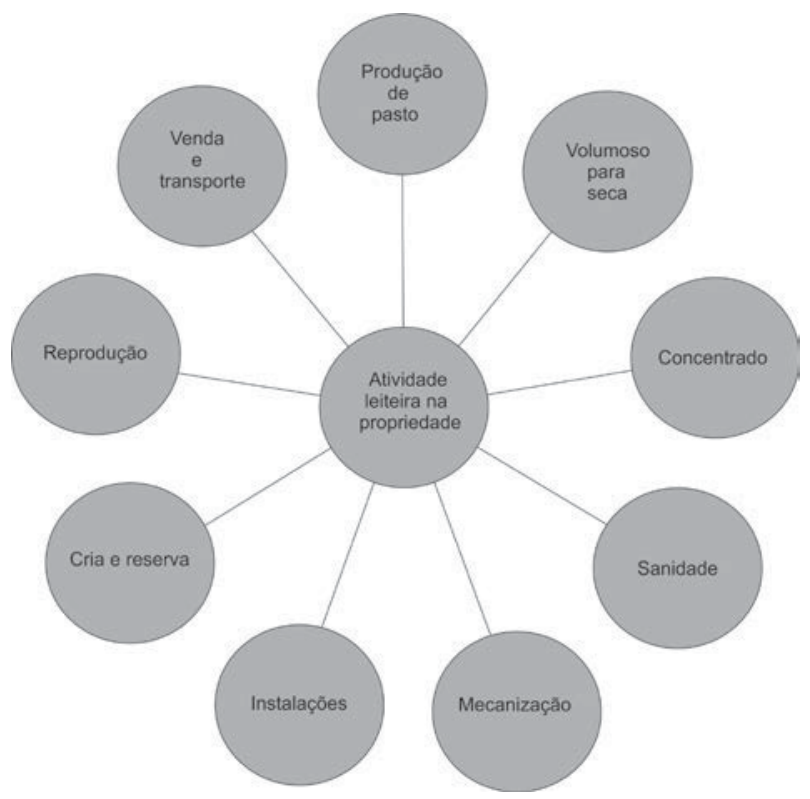

Figura 3: Atividades relacionadas com a pecuária leiteira Fonte: Adaptada de Souza Lima Jr. (2005)

\footnotetext{
${ }_{9}^{9}$ No Brasil também surgiram inúmeros casos de empresas nacionais que se tornaram transnacionais no mercado externo. Fizeram o caminho inverso. Algumas transnacionais de países no âmbito da OCDE já operavam no Brasil antes da abertura do mercado lácteo.

${ }^{10} \mathrm{~A}$ origem das empresas transnacionais do setor pertence em sua maioria aos países membros do organismo.

${ }^{11}$ De acordo com o Zootecnista e professor da UFRRJ, Edinaldo Bezerra, volumosos ou forrageiros são alimentos que contem mais de $18 \%$ de fibra. Abaixo disso são considerados concentrados. O primeiro é pasto, fenos, silagens e capineiras. O segundo são as rações comerciais elaboradas na propriedade, núcleos proteicos com milho e farelos de oleaginosas e de cereais.
}

\section{Programa Balde Cheio}

O programa Balde Cheio foi uma iniciativa da EMBRAPA Pecuária Sudeste e tem como objetivo:

\begin{abstract}
Capacitar, qualificar e atualizar técnicos ligados à extensão rural oficial, privada e autônomos, conceitos e princípios que regem a produção leiteira sustentável sob todos os aspectos, utilizando uma metodologia inovadora de transferência de tecnologia onde uma propriedade leiteira de cunho familiar é utilizada como sala de aula prática por um período mínimo de quatro anos onde acontecerão visitas quadrimestrais do instrutor e mensais do aluno (extensionista) completando o processo de transferência de tecnologia. (CAMARGO, 2014) ${ }^{12}$
\end{abstract}

Foi lançado em 1998 no Estado de São Paulo no município de São Carlos por um grupo de cinco pesquisadores, e gradualmente espalhou-se, por todas as regiões do país. Com o programa Balde Cheio a EMBRAPA espera levar a pesquisa para perto dos usuários.

A ideia básica envolvida era selecionar dentre a gama de práticas já conhecidas àquelas que melhor se ajustam ao sistema de produção particular e adaptar as práticas tecnológicas na exploração considerando as condições biofísicas e socioeconômicas. O programa começou nos Estados de São Paulo e Minas Gerais com sete e cinco agricultores respectivamente, informalmente.

Nesta fase inicial, os pesquisadores da EMBRAPA treinaram diretamente os extensionistas e trabalharam juntamente com eles nas fazendas. Após três anos, o programa teve um impacto positivo sobre as fazendas em termos de produtividade $e$ índices econômicos, $e$ de imediato o programa proporcionou um aumento de autoestima entre os produtores. O objetivo de aumentar a renda através da introdução de tecnologias ao nível da exploração, adaptando os processos e aprendizado com os agricultores foi alcançado (TUPY et al., 2006; CAMARGO et al., 2006). Uma avaliação interna da primeira fase do programa produziu alguns resultados adicionais. Primeiro, adquirir experiência fora do ambiente da fazenda experimental rendeu

\footnotetext{
${ }^{12} \mathrm{O}$ pesquisador da EMBRAPA Pecuária Sudeste, gentilmente enviou por escrito sua leitura deste trabalho fornecendo dados importantes sobre o Balde Cheio e com explicações técnicas pertinentes.
} 
importantes aprendizados sobre como e quando uma tecnologia específica deve ser usada em situações práticas da vida real. Em segundo lugar, o trabalho com os agricultores de base familiar em vez de agricultores mais capitalizados foi mais eficiente (TUPY et al., 2006).

Novo (2012) relata que a avaliação constatou que as taxas de migração dos membros das famílias de agricultores familiares diminuíram, assim como as cargas de trabalho de seus membros, assim eles tiveram mais tempo durante o dia para lazer ou outras atividades. A capacidade para pagar o ensino privado para filhos adolescentes estava mais ao seu alcance. Os agricultores também puderam realizar algumas melhorias na casa, por exemplo, a construção de um banheiro no interior, além de comprar alguns pequenos eletrodomésticos. Além disso, a autoestima dos agricultores aumentou. As experiências com as fazendas mais capitalizadas foram menos positivas. Eles encontraram problemas em aplicar as alterações propostas devido à falta de gestão adequada dentro da fazenda. Naquele momento, enquanto em sua forma atual o programa não poderia garantir assistência de longo prazo, mesmo assim, agricultores de outras regiões vinham solicitar este tipo de apoio.

Após avaliação da primeira fase do programa, o programa Balde Cheio identificou dois elementos principais para o desenvolvimento desta modalidade alternativa ${ }^{13}$ de transferência de tecnologia. Em primeiro lugar, dada a complexidade da produção de leite com suas múltiplas interações entre solo, planta, clima, rebanho de trabalho e gestão, a introdução de inovação requer pesquisadores e técnicos a adotar uma perspectiva ampla que leva em conta todo o processo produtivo. Um segundo elemento diz respeito ao papel dos técnicos. Na primeira fase do Balde Cheio seu papel limitou-se a organização de reunióes e o convite para a participação dos agricultores. Eles raramente participavam na tomada de decisões na fazenda e, consequentemente, não foram diretamente responsáveis pelo resultado final do processo de inovação. Assim, o papel desempenhado pelo técnico de serviço de extensão teve que ser revisto (NOVO 2012).

\footnotetext{
${ }^{13}$ Alternativo no sentido de se criar uma tecnologia e gestão adequadas à realidade de cada produtor rural. O sistema tradicional por imposição top-bottom, utilizados por outros programas de assistência rural, passou a não ser utilizado pelo Balde Cheio, as decisões deveriam ser tomadas pelo produtor e técnico em conjunto.
}

De acordo com Novo (2012), os papéis do pequeno produtor de leite e do extensionista foram invertidos. O programa agora veio a se concentrar em formação de técnicos locais ${ }^{14}$ que foram contratados por uma série de parceiros, como outras agências governamentais, municípios, cooperativas e associações de agricultores ${ }^{15}$. Em geral, os técnicos de serviço em extensão rural têm um conhecimento insuficiente sobre a pecuária leiteira. O novo quadro empregou uma abordagem prática em que a fazenda de caráter familiar era vista como a melhor configuração para formação de técnicos locais. Trabalhando em estreita colaboração com os agricultores durante o curso de um projeto de longo prazo, aumentava a responsabilidade do técnico e do pesquisador.

O programa é um raro exemplo de como reduzir o fosso entre a comunidade científica, neste caso, os programas de investigação avançada dos institutos de pesquisa do governo e sistemas de produção de leite. Uma análise deste programa mostra várias lições para o agricultor familiar orientado sob P\&D e sob a extensão. Tal programa analisa como ele difere da pesquisa e desenvolvimento convencional ${ }^{16}$ dos programas de extensão.

\subsection{Metodologia do Programa}

A capacitação e a troca de informações acontecem na propriedade rural, que se torna uma sala de aula, chamada de unidade demonstrativa (UD). A partir da estruturação da propriedade com base nas orientações do projeto, a unidade demonstrativa passa a ser uma referência na região.

O envolvimento de parcerias distintas entre diferentes elos da cadeia produtiva do leite confere ao projeto uma base sustentável e dinâmica, colaborando para a formação de uma rede de trabalho em que ocorre uma intensa troca de informações e de conhecimentos (EMBRAPA PECUÁRIA SUDESTE, 2006).

\footnotetext{
${ }^{14}$ Multiplicadores treinados pelos técnicos da EMBRAPA Pecuária Sudeste. Em geral oriundos do sistema SENAR, SEBRAE e/ou indicados pelas prefeituras locais.

${ }^{15}$ Foram geradas conexões sociais conhecidas como redes. Uma estrutura social composta por pessoas ou organizações, conectadas por um ou vários tipos de relações, que partilham valores e objetivos comuns.

${ }^{16}$ Programas de pesquisa e desenvolvimentos convencionais em via de regra possuem um pacote pronto a ser aplicado em todas as propriedades. Trata-se de um modelo linear ainda bastante utilizado e eficiente para sistemas equivalentes.
} 
O projeto prevê a discussão de um amplo pacote de conhecimentos e tecnologias para o produtor de leite, que compreende um conjunto escalonado e articulado de técnicas agrícolas, zootécnicas, gerenciais e ambientais (CAMARGO, 2014); como: conservação do solo, recuperação da fertilidade do solo, manejo intensivo de pastagens tropicais adubadas e irrigadas, manejo rotacionado das pastagens, utilização de cana-de-açúcar + ureia no período da seca, realização de exames de brucelose e de tuberculose nos animais $e$ uso de técnicas para irrigação da pastagem.

Esse conjunto de técnicas é complementado com o uso de planilhas de controle zootécnico e econômico; a utilização de um quadro dinâmico de controle reprodutivo, de higiene e de qualidade do leite; a identificação dos animais; a melhoria no padrão genético do rebanho; a anotação de dados climáticos (chuva e temperatura máxima e mínima); e a aplicação de práticas associativistas. Além disso, o uso de instrumentos de controle gerencial tais como planilhas de controle e de análise de custo de produção e de controle zootécnico, tem possibilitado tornar rentável a atividade leiteira nas pequenas propriedades familiares e consequentemente transformá-las em atividade fixadora do homem no campo (TUPY et al., 2006).

Antes de iniciar o processo de mudança e aplicar essa ou aquela tecnologia, o produtor deve compreender a nova postura a ser empregada em seu negócio. Para isso, deve visitar outros produtores com experiência no processo de intensificação da produção acompanhado pelo extensionista da região, buscando obter informações técnicas e econômicas e avaliar o trabalho do profissional que possivelmente lhe dará assistência.

Para fazer parte do Balde Cheio a propriedade que quiser ser uma "sala de aula prática" deverá (CAMARGO, 2014):

a) fazer exames para detecção da brucelose e da tuberculose no rebanho. Se houver casos positivos os animais deverão ser eliminados;

b) permitir que a propriedade receba visitas;

c) fazer sempre o que for combinado entre as partes envolvidas: pesquisador/técnico local/ produtor; $e$

d) passar a fazer controles climáticos (chuva e temperatura máxima e mínima), financeiros (despesas e receitas relativas à atividade) $e$ zootécnicos (parições, cobrições e controle leiteiro mensal).

Como direito terá a visita mensal do técnico local e quadrimestral do pesquisador ou instrutor designado pela EMBRAPA Pecuária Sudeste (CAMARGO, 2014). Após a decisão de mudança, o primeiro passo deve ser analisar, com orientação técnica, as principais limitações e as principais vantagens para a produção intensiva de leite na região (clima, topografia, qualidade das vias de acesso, disponibilidade de insumos, existência de energia elétrica e de empresa ou cooperativa idônea para compra do leite, etc.) e na propriedade (disponibilidade atual de volumosos, situação reprodutiva e sanitária do rebanho, disposição de aguadas e de sombra e qualificação da mão de obra) (CAMARGO et al., 2006).

Em seguida é realizado o planejamento onde deve prever dificuldades e conter a previsão de crescimento para médio e longo prazo, que possibilite visualizar como o negócio estará dentro de alguns anos. No início do plano de trabalho, produtor e técnico devem conversar claramente sobre as reais condições de investimento e de condução da atividade, e ajustar o plano de acordo com essa realidade. As mudanças propostas exigem investimentos para solução das principais limitações apontadas no planejamento. Entretanto, em razão da dificuldade de obtenção de crédito bancário para investimentos, os recursos para o início do trabalho devem ser gerados dentro da propriedade, mesmo que o montante inicial seja pequeno (CAMARGO et al., 2006).

A maioria das fazendas ou sítios possui animais improdutivos, como vacas secas ou vazias, animais em crescimento pouco desenvolvidos, ou animais de lida em excesso, que podem ser vendidos, sem prejuízo para a produção atual ou para o futuro do rebanho. Antes, porém, é necessário que um médico veterinário examine o rebanho, para identificação dos animais improdutivos. Feito o planejamento e definidos os recursos disponíveis, inicia-se a implantação do projeto, investindo em fatores produtivos, principalmente naqueles que atendem às exigências básicas das vacas leiteiras (NOVO; SCHIFFLER, 2006).

Para auxiliar na tomada de decisão e como contrapartida, as propriedades selecionadas para serem 'sala de aula' recebiam o seguinte material/serviço: planilhas 
para controle econômico e zootécnico da atividade, análise do solo, levantamento sanitário do rebanho em relação à brucelose e tuberculose, levantamento planialtimétrico ${ }^{17}$ detalhado, identificação dos animais pertencentes ao rebanho através de brincos numerados, fita para pesagem mensal das fêmeas em crescimento do nascimento à parição, pluviômetro, termômetro de máxima e mínima, quadro magnético circular para gerenciamento da reprodução do rebanho, quadro magnético circular para gerenciamento do crescimento de bezerras e novilhas (EMBRAPA PECUÁRIA SUDESTE, 2006). Atualmente, apenas as planilhas para os controles são oferecidas (CAMARGO, 2014).

Por se tratar de um projeto de desenvolvimento, é fundamental a colaboração de pelo menos um extensionista do município, pois a transferência de tecnologia envolve discussão de conceitos, de princípios e de conhecimentos. Sem a presença desse agente, o trabalho seria tão somente de assistência técnica, missão que não cabe à EMBRAPA; além disso, apenas o produtor assistido seria beneficiado, o que limitaria a abrangência do projeto (CAMARGO et al., 2006b).

Em vez de simplesmente copiar e introduzir tecnologias em velocidade, os agricultores têm de se engajar em um processo mais lento de aprendizagem, que é adaptada às condições específicas econômicas e ambientais da fazenda. Aprender com os outros (aprendizagem social) tem que ser acoplado à experimentação na fazenda (educação ambiental). A experiência dos agricultores que participam do programa (FIGUEIRÓ, 2011; CAMARGO et al., 2006) sugere que a sequência de introdução de tecnologia, muitas vezes, é mais importante para um processo de intensificação do sucesso que a tecnologia proposta em si.

\section{Metodologia e Resultados Obtidos}

Buscou-se neste trabalho, a realização de uma pesquisa exploratória, bibliográfica e de estudo de dois casos acerca dos temas de gestão e tecnologia rural, cadeia produtiva do leite, normatização sani- tária do setor e agricultura familiar, tendo em vista a análise do programa Balde Cheio para analisar suas possibilidades como vetores de promoção e inserção dos pequenos produtores na cadeia produtiva do leite.

Os procedimentos adotados (entrevistas em profundidade) foram baseados e extraídos do modelo publicado em Identificação Participativa de Demandas para Pesquisa \& Extensão (TEIXEIRA, 2009) cujo trabalho contou com a parceria do SENAR-Rio e EMBRAPA Gado de Leite. Foi escolhida a microrregião de Três Rios, por acolher o Instituto Três Rios da Universidade Federal Rural do Rio de Janeiro, instituição acadêmica cujo proponente deste trabalho está lotado, além do município abrigar a planta láctea mais moderna do país pertencente à Nestlé. Tal região, com a microrregião de Vassouras, caracteriza a área de pesquisa deste trabalho.

Após entrevistas realizadas nas propriedades, foi elaborado um modelo da análise SWOT, conforme

Quadro 2, o que facilitaria a visualização sistêmica (visão do todo e da interação entre as partes), e a relação entre cada um dos fatores.

\begin{tabular}{|c|c|}
\hline \multicolumn{2}{|c|}{ AMBIENTE INTERNo } \\
\hline ForÇAS (S) & FraQuezas (W) \\
\hline $\begin{array}{l}\text { Relação interpessoal técnico } \\
\text { e produtor franca e sincera; } \\
\text { Intensificação de áreas } \\
\text { nobres da propriedade; } \\
\text { Comprometimento da família; } \\
\text { Máquinas e equipamentos; } \\
\text { Capital de giro; } \\
\text { Análise amostral do } \\
\text { leite positiva; } \\
\text { Mão de obra capacitada; } \\
\text { Vocação familiar; } \\
\text { Produção diversificada } \\
\text { para o autoconsumo; } \\
\text { Atividades complementares } \\
\text { na propriedade; } \\
\text { Rebanho mestiço (baixa } \\
\text { manutenção); } \\
\text { Baixa ou ausência de mão } \\
\text { de obra de terceiros. }\end{array}$ & $\begin{array}{l}\text { Falta de recursos financeiros; } \\
\text { Dependência do técnico; } \\
\text { Não continuidade do trabalho } \\
\text { familiar (sucessão); } \\
\text { Acesso de pessoas não } \\
\text { autorizadas e de animais } \\
\text { em etapas importantes } \\
\text { (ordenha e curral); } \\
\text { Análise amostral deficitária; } \\
\text { Capacitação e desenvolvimento } \\
\text { de pessoal deficitários; } \\
\text { Rebanho mestiço (baixa } \\
\text { produtividade). }\end{array}$ \\
\hline
\end{tabular}

17 O levantamento planialtimétrico de uma determinada área visa obter com precisão, usando-se métodos e instrumentos adequados, os elementos que permitam a elaboração das plantas topográficas com número suficiente de coordenadas de pontos de superfície do terreno. 


\section{Ambiente Externo}

\section{OPORTUNIDADES (O)}

Visita periódica mensal do técnico do Balde Cheio;

Visita periódica do veterinário privado; Dimensionamento técnico dos insumos a adquirir; Inserção na cadeia do leite; Criação de um selo de qualidade da região; Normatização sanitária atendida (alta qualidade); Acesso facilitado aos programas creditícios oficiais; Coleta da amostra periódica das processadoras;

Aplicação de tecnologias existentes;

Programas de fidelidade e bonificação das processadoras; Diversificação do produto; Associação a um modelo cooperativista.

Quadro 2: Análise S.W.O.T. das Propriedades Visitadas Fonte: Dados da pesquisa

\section{Conclusão}

As mudanças na cadeia produtiva do leite têm afetado não somente os produtores, mas cooperativas, empresas captadoras do leite, e instituições públicas e/ ou privadas de transferência de tecnologia e extensão direta ou indiretamente não fogem à regra. Ambas as entidades reconhecem que essas alterações interferem no desenvolvimento de suas atividades, e assim em sua competitividade, na concentração de linhas de pesquisa e geração de conhecimento. Portanto, tem buscado se adequar a elas com o objetivo de se manter no mercado e atualizados com o setor internacional. Dentre essas mudanças, aquela que tem mais afetado a região brasileira nos últimos anos de forma mais intensa, tem sido o acirramento da concorrência por causa da instalação de grandes empresas processadoras de leite na região. Para se manter no mercado, à medida que há uma busca incessante pela redução dos custos, eles acabam impondo também uma maior competitividade à montante deste processo.
A exigência de incorporação de inovações tecnológicas e gerenciais no processo produtivo da cadeia agroindustrial do leite do município de Valença e região, principalmente entre os pequenos produtores rurais, por exemplo, aquisição de máquinas e equipamentos: tanque de expansão, construção de fosso padronizado, sistema de ligação direta, projetos de irrigação e outros. Ao mesmo tempo, a necessidade de que os pequenos produtores gerenciem sua unidade de produção como: lançamento e controle de dados econômicos, climáticos, pedológicos e zootécnicos, noções de matemática financeira e contabilidade, requerem a participação cada vez mais marcante de um técnico além de auxiliá-lo na elaboração de um plano de negócio que o facilite na solicitação de créditos governamentais.

Uma das grandes virtudes do programa brasileiro é resgatar a autoestima do produtor familiar e demonstrar a ele próprio que ele e sua família são capazes de saírem, às vezes, de situações de extrema pobreza para uma condição de produtor (de fato) inseridos numa cadeia produtiva. Esse resgate da dignidade familiar rural foi visto neste trabalho como um dos fatores mais positivos do programa. Ouvir de um produtor que "o Balde Cheio trouxe para ele a possibilidade de gerar riqueza no campo, caso contrário, poderia estar gerando pobreza na cidade catando latinha", é um dado rico e ao mesmo tempo enfático que o sucesso do Balde Cheio tem sito satisfatório.

O programa Balde Cheio atendeu, dentro de suas limitações valorizar a unidade familiar, o trabalho, a propriedade e o tempo necessário para se atingir à uma remuneração digna, desenvolvendo o meio rural e trazendo estima ao produtor familiar já seria uma grande conquista do programa de transferência. O modelo praticado pelo programa confirmou a possibilidade de se atender à um apelo social com especialização $e$ satisfazer também uma visão econômica com geração de renda e produtiva com inclusão na cadeia do leite.

Vale ressaltar ainda que o proponente deste trabalho tenha buscando atingir os objetivos da pesquisa, o tema é bastante vasto e instigante ao mesmo tempo, uma vez que o recorte analisado da pesquisa se restringiu a uma pequena região e amostra, o que reforça a necessidade contínua de pesquisa. 


\section{REFERÊNCIAS}

ALVES, E. Retorno à escala e mercado competitivo: teoria e evidencias empíricas. Revista Agronegócio, Viçosa, v. 2, n. 3, 2004.

BATALHA, M. (Coord.). Recursos humanos e agronegócio. 1. ed. Jaboticabal: Novos Talentos, GEPAE, 2005.

BELIK, W. Muito além da porteira: mudanças nas formas de coordenação da cadeia agroalimentar no Brasil. Campinas: Unicamp, 1999.

BESSANT, J.; RUSH, H. Building bridges for innovation: the role of consultants in technology transfer. Research Policy, [S.l.], v. 24, p. 97-114, 1993.

BOEHLJE, M.; EIDMAN, V. Farm Management. New York: John Wiley \& Sons, 1984.

\section{CAMARGO, A. C. Informações pessoais sobre o Baldo}

Cheio: revisão da presente tese de doutorado Balde Cheio e Proyecto Lechero - fragilidades e potencialidades de políticas inclusivas e inovadoras para os pequenos produtores de leite. Registro enviado por escrito pelo autor, 2014.

\section{CAMARGO, A. C. et al. Projeto Balde Cheio:} transferência de tecnologia na produção leiteira - Estudo de caso do sítio Boa Vista, de Elisiário, SP. São Carlos: Embrapa Pecuária Sudeste, 2006. p. 8. (Embrapa Pecuária Sudeste, Comunicado técnico 71)

\section{CANZIANI, J. Assessoria administrativa a produtores} rurais no Brasil. 2001. p. 237. Tese (Doutorado) - Escola Superior de Agricultura Luiz de Queiroz da Universidade de São Paulo, Piracicaba, 2001.

COOPER, J. R. A multidimensional approach to the adoption of innovation. Management Decision, [S.I.], v. 36-38, p. 493-502, 1998.

DALMAZO, N.; ALBERTONI, L. A necessidade de um enfoque de administração rural na pesquisa e extensão rural. In: SEMANA DE ATUALIZAÇÃO EM ADMINISTRAÇÃO RURAL, Lages, 1991. Anais... Florianópolis: SAA; EPAGRI; CTA do Planalto Serrano Catarinense, 1992.
DRUCKER, P. Las cinco preguntas más importantes que usted debe formularse sobre su organización sin fines de lucro. Buenos Aires: Editorial Granica, S.A. Serie Comprimisso, 1995.

EDGE, D. Reinventing the wheel. In: JASANOFF, S.; PETERSEN, J. C.; PINCH, T. Handbook of science and technologies studies. Thousand Oaks, Calif: Sage Publications, 1995. p. 3-24.

\section{EMPRESA BRASILEIRA DE PESQUISA} AGROPECUÁRIA SUDESTE. Programa Balde Cheio. São Carlos: Embrapa Pecuária Sudeste, 2006. Disponível em: <http://www.cppse.embrapa.br/balde-cheio>. Acesso em: 20 nov. 2012.

EPAGRI. Manual de referências técnico-econômicas de sistemas de produção agropecuários de Santa Catarina. Florianópolis: Documento n. 218, 2005.

FEDERAÇÂO DA AGRICULTURA, PECUÁRIA E PESCA DO ESTADO DO RIO DE JANEIRO. Diagnóstico da cadeia produtiva do leite do Estado do Rio de Janeiro. Rio de Janeiro: FAERJ/SEBRAE-RJ, 2010.

FIGUEIRÓ, I. Entrevista: Artur Chinelato de Camargo.

Revista Mundo do Leite, [S.l.], n. 50, setembro, 2011. Disponível em: <http:/www.portaldbo.com.br/novoportal/ site/MundoDoLeite>. Acesso em: 13 jan. 2013.

GOMES, A. P. Impactos das transformações da produção de leite no número de produtores $e$ requerimentos de mão de obra e capital. 1999. p. 161.Tese (Doutorado) - Universidade Federal de Viçosa, Viçosa, 1999.

GOMES; FERREIRA FILHO, J. B. S. Economias de escala na produção de leite: uma análise dos Estados de Rondônia, Tocantins e Rio de Janeiro. Revista de Economia Rural, [S.l.], v. 45, n. 3, p. 591-619, 2006.

GUEDES, C.; ROSÁRIO, J. Informação e conhecimento: os impactos na reorganização do mercado e do trabalho. Desenvolvimento em Questão, [S.I.], v. 5, n. 5 , p. 9-34, jan.-jun. 2005.

\section{INSTITUTO BRASILEIRO DE GEOGRAFIA E} ESTATÍSTICA. Censo Agropecuário 2006. [2006]

Disponível em: <http://www.ibge.gov.br/home/estatistica/ economia/agropecuaria/censoagro/brasil_2006/Brasil_ censoagro2006.pdf>. Acesso em: 22 dez. 2012. 
INSTITUTO DE ESTUDOS SOCIAIS APLICADOS. Del desarrollo rural al desarrollo territorial: reflexiones a partir de la experiencia española (Primer Documento). In: FORO IESA SOBRE LA COHESIÓN DE LOS TERRITORIOS RURALES, 2009. Anais... Córdoba, España, 2009, p. 37.

JANK, M. S.; FARINA, E. M.; GALAN, V. B.

O agribusiness do leite no Brasil. São Paulo: Editora Milkbizz, 1999.

KLERKX, L.; LEEUWIS, C. Balancing multiple interests: embedding innovation intermediation in the agricultural knowledge infrastructure. Technovation, [S.I.], v. 25, p. 364-378, 2008.

MEIRA, J. Sucesso econômico e perfil estrategista empreendedor de produtores rurais: $\mathrm{o}$ caso Nilo Coelho. 1996. p. 76. Dissertação (Mestrado) Universidade Federal de Lavras, Lavras, MG, 1996.

NANTES, J. F. D.; SCARPELLI, M. Gestão da produção rural no agronegócio. In: BATALHA, M. O. (Coord.).

Gestão agroindustrial. 3. ed. São Paulo: Atlas, 2007. Cap. 10, p. 556-584.

NORONHA, J. F.; NUNES, C. L. Análise da rentabilidade da atividade leiteira no Estado de Goiás. Goiânia: UFG, 2001.

NOVO, A. L. M. Islands of dairy in a sea of sugarcane: the future of family dairy farming in Brazil. 2012. p. 140. Tese (Doutorado) - Wageningen University, Wageningen, 2012.

NOVO, A. L. M.; SCHIFFLER, E. Princípios básicos para a produção econômica de leite. São Carlos: EMBRAPA Pecuária Sudeste, 2006. p. 33. (EMBRAPA Pecuária Sudeste, Documentos 49)

OLINGER, G. Extensão Rural: verdades e novidades. 1. ed. Florianópolis: EPAGRI, , 1998.

ROMEIRO, A. R. Meio ambiente e dinâmica de inovações na agricultura. São Paulo: Anablume/ FAPESP, 2004.

SCHWARTAZMAN, S. A pesquisa científica e o interesse público. Revista Brasileira de Inovação, [S.I.], v. 1, p. 361-395, 2002.
SERVIÇO NACIONAL DE APRENDIZAGEM RURAL. Relatório de atividades. 2009. Disponível em: <www. senar.org.br/atividades/relatorios > . Acesso em: $10 \mathrm{fev}$. 2012.

SHULTZ, C.; KITCHEN, P. Integrated Communications in U.S. Advertising. Journal of Advertising Research, [S.I.], v. 37, p. 7-18, 1997.

SOUZA LIMA JR., A. Assistência técnica da produção de leite: estudo de caso do Projeto Educampo. 2005. p. 94. Dissertação (Mestrado) - Escola de Agronomia/ Universidade Federal de Goiânia, Goiânia, GO, 2005.

\section{TEIXEIRA, S. R. Getting the priorities right:}

stakeholder involvement for a holistic view of research and extension priorities in the Australian and Brazilian industries. 2004. p. 277. $\mathrm{PhD}$ (Thesis) - University of Queensland, Queensland, Australia, 2004.

Identificação participativa de demandas para pesquisa \& extensão. Juiz de Fora: Embrapa Gado de Leite, 2009.

TUPY, O.; PRIMAVESI, O; CAMARGO, A. C. Avaliação dos impactos econômicos, sociais e ambientais de tecnologias da Embrapa Pecuária Sudeste: técnicas de produção intensiva aplicadas a propriedades familiares produtoras de leite. São Carlos: Embrapa Pecuária Sudeste, 2006. 38 p. (Embrapa Pecuária Sudeste:

Documentos 57)

VILELA, D. Cenário atual e perspectivas futuras de PD\&I no Brasil. In: XI CONGRESSO INTERNACIONAL DO LEITE. Goiânia: Embrapa Gado de Leite, 2012. Anais... Goiânia: Embrapa Gado de Leite, 2012.

VILELA, D.; BRESSAN, M. Restrições técnicas, econômicas e institucionais ao desenvolvimento da cadeia produtiva do leite no Brasil. Brasília: MCT/ CNPq/PADCT, Juiz de Fora: Embrapa CNPGL, 1999. p. 211. Juiz de Fora, MG: 1999.

VOLPI, R.; BRESSAN, M. Bases para o programa de qualificação e habilitação de mão de obra para o agronegócio do leite. In: GOMES, A. T.; LEITE, J. L.; CARNEIRO, A. V. (Org.). O agronegócio do leite no Brasil. Juiz de Fora: Embrapa Gado de Leite, 2001. p. 111-122. 